Clowes, R. C. (1958). J. gen. Microbiol. 18, 154-172

\title{
Investigation of the Genetics of Cysteineless Mutants of Salmonella typhimurium by Transduction
}

\author{
By R. C. CLOWES \\ Department of Genetics, Carnegie Institution of Washington, \\ Cold Spring Harbor, N.Y., U.S.A.*
}

SUMMARY: The genetic investigation of forty-three phenotypically classified cysteineless mutants of Salmonella typhimurium by means of transduction suggests that in forty-one of the mutants, strains of similar phenotype result from mutations occurring at a series of sites which form a closely linked group, presumably situated within a single gene locus. Five such loci have been identified.

Only two of these five presumptive loci are linked, and within these linked loci an unusually high proportion of mutations to auxotrophy appear to result from a chromosomal deficiency. Another locus which is linked to an array of loci controlling tryptophan biosynthesis shows biochemical heterogeneity within the locus.

The transfer of hereditary characters between strains of Salmonella typhimurium by means of temperate bacteriophage (transduction) was first described by Zinder \& Lederberg (1952). It is believed that during the process of lytic development in one strain (donor), a proportion of the phage particles incorporate a fragment of bacterial genetic material. When such particles infect another strain (recipient), this fragment of the bacterial genome is transferred, together with the genetic material of the phage. In those recipient cells which survive the infection, the fragment may replace the homologous part of the genetic material of these cells. This latter process has been shown to be accomplished by a mechanism analogous to crossing-over (Demerec \& Demerec, 1956). The incorporated fragment is apparently small, since in most instances only a single discrete character can be transduced at a time, although instances of simultaneous transfer of apparently linked characters have been reported (Stocker, Zinder \& Lederberg, 1953; Demerec et al. 1954; Demerec \& Hartman, 1956; Hartman, 1956; Yura, 1956).

The efficiency with which non-exacting (prototrophic) cells may be produced after treatment of one mutant with phage propagated on another mutant has been studied in detail among a large number of separately isolated auxotrophs of Salmonella typhimurium by Demerec and his co-workers. These mutants which have a growth requirement for a specific amino acid, vitamin or purine were classified phenotypically by their ability to grow on certain intermediates in the synthetic pathway of the particular growth factor, and also by cross-feeding tests between mutants responding to different precursors in the same pathway. Transduction experiments showed when two mutants have an auxotrophic requirement for different growth factors, that under standard

* Present address: M.R.C. Microbial Genetics Research Unit, Hammersmith Hospital, Ducane Road, London, W. 12. 
conditions, the number of prototrophs formed is similar to that found when either mutant is infected with phage derived from the lysis of wild-type cells. However, although transductions between most pairs of the mutants of the same phenotypic group were found to give rise to prototrophs, they were produced in much smaller numbers than when wild-type cells were used as the source for the phage. This suggested that these apparently phenotypically identical mutants (manifesting the same metabolic block) were not genetically identical, but that the mutational sites involved were probably very closely linked, so that crossing-over between them, required to produce a prototroph, was infrequent, which would result in a decreased yield of prototrophs by transduction (Demerec et al. 1954).

The evidence is consistent with the view that a gene locus extends over a finite region of the chromosome, the integrity at many points along this region being necessary to ensure the continuation of the particular function which is controlled by the gene in the wild-type cell. Changes occurring at any one of these different points (sites) within this region will thus give rise to mutants which will be of a similar phenotype, in that the function controlled by the gene is either deficient or modified in each mutant. The mutational sites are separable by crossing-over, which can thus give rise to the wild-type genome. The term 'gene' or 'gene locus' is hereafter used to mean that unit, defined by terms such as 'complex locus', which corresponds to the gene as a physiological unit of function, and which can be further subdivided by either mutation or recombination. Mutations occurring within this locus will thus produce a series of mutants which are 'non-identical alleles' of the same gene locus, and which resemble each other in the loss or modification of the particular function which is under the control of the gene concerned (Demerec, 1956a; Benzer, 1957).

In general, within one locus, the nearer the relative location of two sites, the smaller is the yield of prototrophs obtained by transduction of one mutant by phage propagated on the other (Demerec et al. 1954).

The investigation of a series of cysteineless mutants of Salmonella typhimurium, which have been previously characterized phenotypically (Clowes, 1958 ) is reported in this paper.

\section{METHODS}

Salmonella typhimurium, LT-2 (Zinder \& Lederberg, 1952) was used as a wildtype strain.

Cysteineless mutants used in this study comprised the following strains:

(a) cys $A$ mutants (cys-1, $-3,-5,-13,-20,-21,-22$ and -32$)$ in which sulphite can replace the cysteine requirement.

(b) cysB mutants (cys-4, $-10,-12,-14,-15,-16,-18,-24,-25,-27,-40,-41$ and $-45)$ in which the cysteine requirement can be replaced by high concentrations (1 mg. S/ml.) of thiosulphate.

(c) cysC mutants (cys-7, $-38,-43$ and -47$)$ whose cysteine requirement can be either sulphite or thiosulphate ( $>10 \mu \mathrm{g}$. S $/ \mathrm{ml}$.).

(d) cys $D$ mutants (cys-23, -28, -29, -36, -37, -42, -44, -46, -48, -49, -50 and -51 ) able to replace the cysteine requirement with thiosulphate ( $>10 \mu \mathrm{g} . \mathrm{S} / \mathrm{ml}$.). 
(e) cys $E$ mutants $(c y s-2,-6,-8,-11,-17$ and -30$)$ whose growth requirement for cysteine cannot be replaced by any inorganic sulphur source.

Their isolation and classification is described elsewhere (Clowes, 1958).

Phage stocks used in all transductions were derived from the temperate form $\left(\mathrm{H}_{1}\right)$ of phage PLT-22 of Zinder \& Lederberg (1952). The stocks were prepared by infecting logarithmic-phase cultures of the donor strain $\left(10^{8}\right.$ bacteria $/ \mathrm{ml}$. $)$ in nutrient broth with phage at a multiplicity (phage particles per bacterium) of $\mathbf{0 . 0 0 5}$. The previous host of the phage is immaterial, since transducing ability is not maintained through successive lytic propagations of the phage (Zinder, 1955). After aeration for $5 \mathrm{hr}$. at $37^{\circ}$, the partially lysed cultures were centrifuged at $3000-5000 \mathrm{~g}$ for $15 \mathrm{~min}$., to remove unlysed bacteria and debris, and the supernatants were further centrifuged at $12,000 \mathrm{~g}$ for $1 \mathrm{hr}$. The phage was thus sedimented as a translucent pellet, which, after decantation of the supernatant, was suspended in approximately one-tenth the original volume of T2 buffer (Hershey \& Chase, 1952). Residual bacteria were killed by the addition of chloroform, which was removed by aeration after $10 \mathrm{~min}$. These concentrated phage preparations were then assayed, the titre at this stage being usually between $4 \times 10^{11}$ and $10^{12}$ phage particles $/ \mathrm{ml}$. Stocks were maintained at $4^{\circ}$, at which temperature their titre was constant over several months.

Phage assays were made by the agar layer technique (Adams, 1950), using strain LT-2 as indicator.

Media used were as detailed previously (Clowes, 1958).

Transduction was effected by mixing recipient bacteria in the late logarithmic phase $\left(10^{9}\right.$ cells $/ \mathrm{ml}$.) with phage at a multiplicity of 5 at $37^{\circ}$, and holding at this temperature for at least 5 min. to allow adsorption. This mixture was then spread in $0.1 \mathrm{ml}$. vol. over enriched minimal agar plates by means of a glass spreader. Controls of uninfected bacteria were plated on the same medium, as was an appropriately diluted phage suspension. In order to control variations in transduction efficiency due to apparent physiological variation in parallel cultures of the same recipient strain, every culture in each series of transductions was also treated with a standard preparation of phage which had been propagated on wild-type cells. Thus for each mutant the numbers of prototrophs produced by phages grown on other mutants could be expressed in terms of the numbers of prototrophs produced by phage propagated on wildtype cells. All transduction mixtures were plated on at least three plates, with three control plates. All recipient strains were sensitive to PLT-22. Colonies were counted after $36 \mathrm{hr}$. incubation at $37^{\circ}$, and where these consisted of various phenotypes (e.g. Tables 5 and 6 ), the numbers of the individual phenotypes were scored after replication by the velvet-pad technique (Lederberg \& Lederberg, 1952) on appropriately supplemented minimal agar plates which were incubated for $6 \mathrm{hr}$. at $37^{\circ}$.

In most experiments, a few isolated colonies were found on the plates spread with uninfected bacteria. These colonies were stably prototrophic, and probably arose as a result of either back-mutation (reversion) or further mutation at a different locus (suppression), in some rare mutant cells. In general, these colonies occurred with a frequency of about one for every $10^{8}$ cells plated, and 
in these instances, the yields of prototrophic colonies arising on plates spread with the phage + bacteria mixture were corrected for this phenomenon. In rare instances, a score or more colonies were produced, presumably due to mutation at an early stage after subculture and under these circumstances, the transduction was discarded and the experiment repeated with a fresh subculture. Since all mutants used in this study had been previously screened for stability in this direction, and unstable mutants which invariably produced prototrophs at a frequency greater than about 1 in $10^{7}$ cells plated had been previously discarded (Clowes, 1958), a further subculture usually resulted in a low colony count on the uninfected bacteria control plates. With some mutants, no colonies were detected on minimal agar plates spread with the usual $10^{8}$ inoculum. With certain of these strains, no reversion was noted on ten or more plates spread with $10^{9}$ cells. These non-reverting strains were restricted to certain members of the cysD group ( $D_{2}$ mutants) which had been previously differentiated (Clowes, 1958) from the remainder of $c y s D$ group $\left(D_{1}\right.$ mutants) by their inability to support the growth of cysC mutants by syntrophy (cys $D-28$, $-29,-36,-37,-42$ and -49 ).

In all instances, cultures of mutants infected with phage derived from the lysis of a separate subculture of the same mutant (homologous phage) gave numbers of prototrophic colonies which were similar to the corresponding uninfected controls.

In some experiments, where the numbers of colonies appearing after transduction were small, the multiplicity of the phage was increased to 25 , and ten plates of both transduction mixture and controls were spread. In these instances it has been assumed that the efficiency of transduction varies linearly with multiplicities between 5 and 25 (Zinder \& Lederberg, 1952), and the results are expressed as those expected at the lower multiplicity.

Abortive transduction of nutritional characters was investigated by the examination of plates spread with a transducing mixture of phage and bacteria for 'minute colonies' (Ozeki, 1956). The term 'abortive transduction' was coined by Stocker et al. (1953) for the 'trail' phenomenon observed in experiments involving the transduction of motility. These authors suggested that in certain instances after infection the genetic fragment introduced into the recipient cell might not replicate and was not eliminated. A similar mechanism was invoked by Ozeki (1956) to explain phenomena observed during the study of transduction of nutritional characters. In this instance, a number of 'minute' colonies were observed, in addition to the larger prototrophic colonies, on minimal plates spread with the transduction mixture. Experimental evidence was consistent with the hypothesis that each 'minute' colony contained only one cell which was capable of producing a further 'minute' colony. Unilinear inheritance of a non-replicating non-eliminated fragment carrying the dominant wild-type allele of a nutritional mutation was invoked to explain the phenomenon which was considered analogous to the 'trail' phenomenon described by Stocker et al. (1953). The observation of 'minute' colonies was first made in transductions using phage derived from wild-type donors, but it was later noted that phage propagated on certain mutants was 
also capable of eliciting 'minute' colony formation when used to infect certain other mutants. However, when the phage was derived from a mutant which was phenotypically similar to the recipient strain, so that the mutational sites of both donor and recipient strains were located within the same gene locus controlling the same function, 'minute' colonies did not develop. Conversely, phage propagated on strains whose sites of mutation were not in the same functional unit as that of the recipient strain invariably gave rise to 'minute' colonies.

The ability of two mutants to produce 'minute' colonies in this manner suggests, therefore, that the mutational sites of recipient and donor strains are situated in different functional units, and thus in different gene loci. Abortive transduction seems therefore capable of differentiating a series of linked mutational sites into separate gene loci in the absence of any biochemical test, and as such seems comparable to the test for complementarity of two mutants combined in a heterokaryon (Pontecorvo, 1952).

\section{RESULTS}

Transduction was carried out with almost all the possible combinations of mutants and in both directions within each of the phenotypic groups of mutants designated as $c y s B, C, D$ and $E$. With certain exceptions, therefore, each mutant of a group was treated with phage grown on every member of that group (Tables 1-3). In addition, each mutant was treated with phage from the same wild-type lysate. It will be seen that there is a large variation in the efficiency with which prototrophs were produced by different mutants when so infected. Moreover, there was an overall twofold variability in the yield of prototrophs from different subcultures of the same strain when treated with any phage. However, the relative efficiency with which a certain subculture of any one strain produced prototrophs when infected by phage propagated on a variety of donor strains, including wild-type, was fairly constant. This led to the expression of prototrophic yields as a fraction of the prototrophs produced by the same subculture of the strain when infected with wild-type phage.

In general, the yield of prototrophic colonies obtained by transduction between mutants of the same phenotypic group was lower than the corresponding yield involving wild-type donors or phenotypically dissimilar mutants. However, in the case of $c y s C$ and $c y s D$ mutants, many intragroup transductions gave rise to larger numbers of prototrophs than certain intergroup transductions. Each mutant in both groups was therefore treated with phage from every member of both groups (Table 2). Furthermore, cys-48 and cys-50, classed as cys $D$ mutants by phenotype, behaved in all transductions tested as though unlinked to any other mutant (including those of either the cysC or cys $D$ group), in giving yields of prototrophs of the same order as with wild-type donors, although giving reduced yields of prototrophs in transductions between each other (Table 2).

Transduction among the cys $A$ group of mutants has been previously described by Demerec (1955). In this study, in all possible crosses between cys $A-1$, 
$-3,-5,-13,-20,-21$ and -22 , and in further studies involving cys-32 (Demerec, unpublished) the maximum yield of prototrophs in any one cross was $44 \%$, that found using phage from the wild-type strain. However, the reciprocal of this particular inter cys $A$ cross gave only $14 \%$ wild-type yield, and three only of the total possible sixty-four combinations (including homologous crosses) gave yields of prototrophs greater than $10 \%$ of the corresponding yield using

\section{Table 1. Frequency of production of prototrophic colonies in transductions between members of cysB group}

Phages grown on

(a) Mutants

\begin{tabular}{|c|c|c|c|c|c|c|c|c|c|c|c|c|c|c|}
\hline \multirow{2}{*}{$\begin{array}{c}\text { Recipient } \\
\text { bacteria }\end{array}$} & & \multirow{2}{*}{$\begin{array}{l}\text { Wild- } \\
\text { type }\end{array}$} \\
\hline & $c y s-4$ & -10 & -12 & -14 & -15 & -16 & -18 & -24 & -25 & -27 & -40 & -41 & -45 & \\
\hline$y s-4$ & 0 & 0.5 & .* & * & * & $*$ & 1.8 & 0.9 & * & $*$ & 1.2 & 0.8 & $8 \cdot 3$ & 2800 \\
\hline$s-10$ & 0 & 0 & $6 \cdot 9$ & $6 \cdot 2$ & $9 \cdot 6$ & $3 \cdot 6$ & $4 \cdot 1$ & $1 \cdot 6$ & $4 \cdot 1$ & 3.7 & $4 \cdot 0$ & $4 \cdot 4$ & $3 \cdot 2$ & 474 \\
\hline$y s-12$ & * & $1 \cdot 3$ & 0 & $2 \cdot 0$ & $3 \cdot 9$ & 1 . & 1.7 & 1.2 & $2 \cdot 0$ & $6 \cdot 7$ & $3 \cdot 0$ & $4 \cdot 3$ & $3 \cdot 0$ & 104 \\
\hline s-14 & * & $1 \cdot 6$ & $2 \cdot 1$ & $\mathbf{0}$ & 1.8 & o. & 0.2 & 0.5 & $5 \cdot 0$ & $\mathbf{2 \cdot 2}$ & $1 \cdot 4$ & .7 & $18 \cdot 0$ & 792 \\
\hline$/ s-15$ & * & $8 \cdot 0$ & $10 \cdot 1$ & $11 \cdot 2$ & 0 & $5 \cdot 4$ & $9 \cdot 2$ & $18 \cdot 3$ & $13 \cdot 3$ & $32 \cdot 5$ & $28 \cdot 5$ & $32 \cdot 1$ & $36 \cdot 3$ & 1096 \\
\hline$y s-16$ & * & 1.8 & $1 \cdot 9$ & 0 . & $3 \cdot 5$ & $\mathbf{0}$ & $0 \cdot 2$ & 1 . & 1.8 & $1 \cdot 1$ & 0.5 & $1 \cdot 4$ & $7 \cdot 7$ & 979 \\
\hline cys -18 & $3 \cdot 0$ & $0 \cdot 6$ & $2 \cdot 6$ & $0 \cdot 1$ & $3 \cdot 1$ & 0 . & 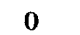 & 0.4 & 0.5 & 0.3 & 0.9 & 0.5 & $2 \cdot 1$ & 2964 \\
\hline$y s-2$ & $3 \cdot 0$ & $1 \cdot 5$ & $2 \cdot 9$ & $1 \cdot 1$ & $5 \cdot 2$ & $0 \cdot 6$ & 0.5 & o & $0 \cdot 1$ & $0 \cdot 6$ & 0.6 & $6 \cdot 2$ & $0 \cdot 8$ & 5175 \\
\hline s- & * & $6 \cdot 5$ & 5 & 1 . & $6 \cdot 3$ & 0 . & 0.7 & 0.7 & o & $2 \cdot 5$ & $1 \cdot 4$ & 4.5 & $14 \cdot 0$ & 2130 \\
\hline s. & * & $4 \cdot 9$ & $2 \cdot 4$ & 1 & 8 . & 0 & 0. & 0 & 2 . & $\mathbf{0}$ & $1 \cdot 0$ & 3 & $7 \cdot 5$ & 888 \\
\hline$s-40$ & $7 \cdot 3$ & $11 \cdot 4$ & 1.9 & 0.5 & 5 . & 0 . & 0. & $\mathbf{0}$ & 0 & 0.8 & 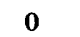 & $1 \cdot 0$ & $11 \cdot 0$ & 1263 \\
\hline $8-41$ & $4 \cdot 2$ & $2 \cdot 4$ & $1 \cdot 3$ & $1 \cdot 1$ & $5 \cdot 7$ & 0.6 & $8 \cdot 0$ & $4 \cdot 8$ & $1 \cdot 4$ & $1 \cdot 4$ & 0.5 & 0 & 1.9 & 1343 \\
\hline cys -45 & $3 \cdot 1$ & 4.0 & 0.5 & 1.0 & 23.9 & $2 \cdot 4$ & 0.5 & $1 \cdot 3$ & 0.75 & 1.0 & $1 \cdot 4$ & 1.5 & 0 & 1517 \\
\hline cysD-23 & 13 & 71 & 57 & 43 & 58 & 64 & 37 & 40 & 75 & 59 & 79 & 82 & 108 & 1265 \\
\hline
\end{tabular}

(a) Each figure represents, for each bacterial strain, the value:

$\frac{\text { number of prototrophic colonies obtained with phage grown on mutant }}{\text { number of prototrophic colonies obtained with phage grown on wild-type cells }} \times 100$.

Each plate was spread with $2 \times 10^{8}$ cells and $10^{8}$ phage which had been incubated together at $37^{\circ}$ for 10 min. The figures shown are the average of at least two separate experiments, in each of which a minimum of three plates were used for each mixture.

(b) Figures for phage grown on wild-type represent total number of colonies appearing on three plates each spread with $2 \times 10^{8}$ mutant cells and $10^{9}$ phage particles in a typical experiment.

* No crosses made.

the wild-type strain as donor. The results of transduction of certain of the cysB mutants included in Table 1 have previously been reported by Demerec, Blomstrand \& Demerec (1955). From these experiments, and from those summarized in Tables 1-3 with the exception of cys-48 and cys-50, the cysteineless mutants can thus be divided into four transduction groups corresponding respectively with the groups $c y s A, c y s B, c y s E$ and $(c y s C+c y s D)$, previously established by the study of the nutritional requirements of the mutants (Clowes, 1958).

Linkage between groups was investigated by several methods.

(1) Yield of prototrophic colonies from transduction between representative members of different phenotypic groups. In these experiments, Table 4 shows the yields of prototrophs to be of the same order as those observed with wildtype donor phage except between $c y s C$ and $c y s D$ mutants (cf. Table 2), where 


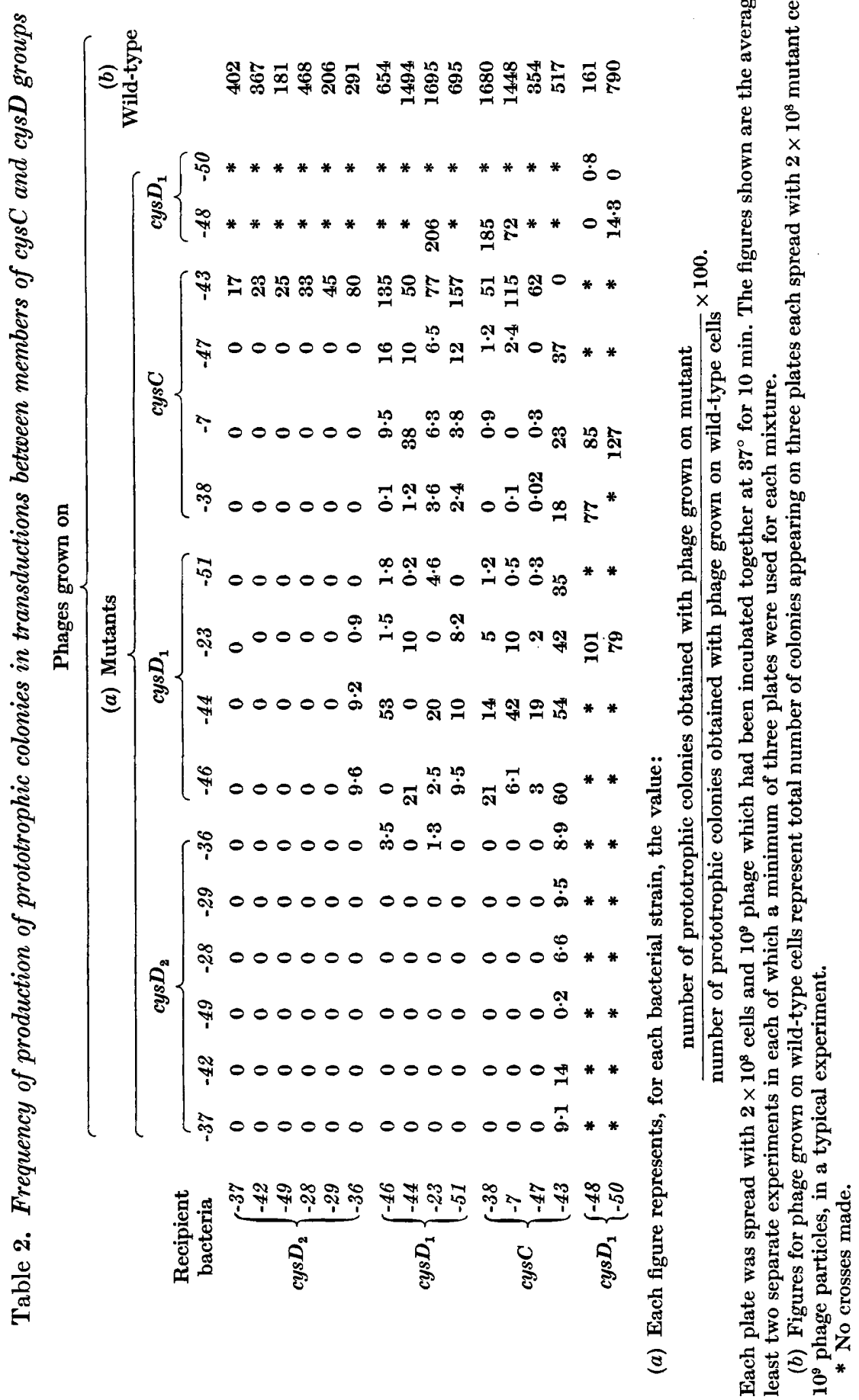


Table 3. Frequency of production of prototrophic colonies in transductions between members of cysE group

Phages grown on

\begin{tabular}{|c|c|c|c|c|c|c|c|}
\hline \multirow{2}{*}{$\begin{array}{c}\text { Recipient } \\
\text { bacteria }\end{array}$} & \multicolumn{6}{|c|}{ (a) Mutants } & \multirow{2}{*}{$\begin{array}{c}(b) \\
\text { Wild-type }\end{array}$} \\
\hline & cys -2 & cys -6 & cys -8 & cys -11 & cys -17 & cys -30 & \\
\hline cys-2 & 0 & 0 & $1 \cdot 1$ & 0.5 & $2 \cdot 3$ & 0 & 336 \\
\hline cys -6 & 0 & 0 & $1 \cdot 2$ & $5 \cdot 9$ & $3 \cdot 2$ & 0 & 512 \\
\hline cys -8 & $\mathbf{0}$ & 0 & 0 & $0 \cdot 4$ & 0 & $2 \cdot 6$ & 327 \\
\hline cys-11 & 0.5 & $6 \cdot 0$ & $0 \cdot 2$ & 0 & $1 \cdot 3$ & $1 \cdot 4$ & 381 \\
\hline eys -17 & $1 \cdot 0$ & $\mathbf{0}$ & 0 & $2 \cdot 9$ & 0 & $0 \cdot 3$ & 278 \\
\hline cys -30 & $\mathbf{0}$ & 0 & $\mathbf{0}$ & $\mathbf{3} \cdot \mathbf{0}$ & $8 \cdot 6$ & 0 & 276 \\
\hline cysD D-23 & 84 & 60 & 39 & 95 & 97 & $\mathbf{5 4}$ & 1011 \\
\hline
\end{tabular}

(a) Each figure represents, for each bacterial strain, the value:

$\frac{\text { number of prototrophic colonies obtained with phage grown on mutant }}{\text { number of prototrophic colonies obtained with phage grown on wild-type cells }} \times 100$.

Each plate was spread with $2 \times 10^{8}$ cells and $10^{9}$ phage which had been incubated together at $37^{\circ}$ for $10 \mathrm{~min}$. The figures shown are the average of at least two separate experiments in each of which a minimum of three plates were used for each mixture.

(b) Figures for phage grown on wild-type cells represent total number of colonies appearing on three plates each spread with $2 \times 10^{8}$ mutant cells and $10^{8}$ phage particles, in a typical experiment.

Table 4. Frequency of production of prototrophic colonies in transductions between cysteineless mutants of various phenotypic groups

Phages grown on

\begin{tabular}{|c|c|c|c|c|c|c|c|c|c|c|c|c|c|}
\hline \multirow{2}{*}{$\begin{array}{c}\text { Recipient } \\
\text { bacteria }\end{array}$} & \multicolumn{2}{|c|}{ cys $A$} & \multicolumn{4}{|c|}{ cysB } & \multicolumn{3}{|c|}{ cys $C$, cys $D$} & \multicolumn{3}{|c|}{ cysE } & \multirow{2}{*}{$\begin{array}{l}\text { cysD } \\
-48\end{array}$} \\
\hline & -3 & -20 & -4 & -10 & -18 & -24 & -7 & -38 & -23 & -2 & -11 & -30 & \\
\hline cys $A\left\{\begin{array}{l}-3 \\
-20\end{array}\right.$ & $\begin{array}{l}\mathbf{0} \\
\mathbf{0}\end{array}$ & $\begin{array}{l}\mathbf{0} \\
0\end{array}$ & $\begin{array}{l}157 \\
171\end{array}$ & $\begin{array}{l}185 \\
247\end{array}$ & $\begin{array}{l}287 \\
206\end{array}$ & $\begin{array}{l}141 \\
120\end{array}$ & $\begin{array}{l}47 \\
52\end{array}$ & $\begin{array}{r}205 \\
62\end{array}$ & $\begin{array}{l}155 \\
125\end{array}$ & $\begin{array}{l}75 \\
97\end{array}$ & $\begin{array}{l}114 \\
117\end{array}$ & $\begin{array}{r}219 \\
90\end{array}$ & $\begin{array}{r}55 \\
220\end{array}$ \\
\hline $\operatorname{cys} B\left\{\begin{array}{l}-4 \\
-10 \\
-18 \\
-24\end{array}\right.$ & $\begin{array}{r}102 \\
52 \\
88 \\
75\end{array}$ & $\begin{array}{r}53 \\
32 \\
132 \\
46\end{array}$ & $\begin{array}{l}\mathbf{0} \\
\mathbf{0} \\
\mathbf{3} \\
\mathbf{3}\end{array}$ & $\begin{array}{l}0.5 \\
0 \\
0.6 \\
1.5\end{array}$ & $\begin{array}{l}1 \cdot 8 \\
4 \cdot 2 \\
0 \\
0 \cdot 5\end{array}$ & $\begin{array}{l}0 \cdot 9 \\
1 \cdot 6 \\
0 \cdot 4 \\
0\end{array}$ & $\begin{array}{r}61 \\
40 \\
102 \\
56\end{array}$ & $\begin{array}{l}24 \\
51 \\
89 \\
92 \cdot 5\end{array}$ & $\begin{array}{r}75 \\
59 \\
45 \\
126\end{array}$ & $\begin{array}{l}32 \\
70 \\
66 \\
35\end{array}$ & $\begin{array}{l}46 \\
86 \\
77 \\
53\end{array}$ & $\begin{array}{r}30 \\
87 \\
111 \\
116\end{array}$ & $\begin{array}{c}* \\
66 \\
* \\
47\end{array}$ \\
\hline $\begin{array}{l}\text { cys } C\left\{\begin{array}{l}-7 \\
-38\end{array}\right. \\
\text { cys } D-23\end{array}$ & $\begin{array}{r}133 \\
152 \\
59\end{array}$ & $\begin{array}{l}148 \\
147 \\
119\end{array}$ & $\begin{array}{l}131 \\
146 \\
113\end{array}$ & $\begin{array}{r}68 \\
105 \\
83\end{array}$ & $\begin{array}{r}94 \\
150 \\
91\end{array}$ & $\begin{array}{r}129 \\
133 \\
40\end{array}$ & $\begin{array}{l}0 \\
0 \cdot 9 \\
6 \cdot 3\end{array}$ & $\begin{array}{l}0 \cdot 1 \\
0 \\
3 \cdot 6\end{array}$ & $\begin{array}{r}10 \\
5 \\
0\end{array}$ & $\begin{array}{r}124 \\
66 \\
84\end{array}$ & $\begin{array}{r}102 \\
81 \\
95\end{array}$ & $\begin{array}{l}90 \\
72 \\
54\end{array}$ & $\begin{array}{r}72 \\
185 \\
206\end{array}$ \\
\hline cys $E\left\{\begin{array}{l}-2 \\
-11 \\
-30\end{array}\right.$ & $\begin{array}{r}161 \\
88 \\
73\end{array}$ & $\begin{array}{l}136 \\
206 \\
153\end{array}$ & $\begin{array}{l}154 \\
175 \\
112\end{array}$ & $\begin{array}{r}95 \\
81 \\
111\end{array}$ & $\begin{array}{r}80 \\
133 \\
61\end{array}$ & $\begin{array}{l}67 \\
57 \\
88\end{array}$ & $\begin{array}{l}125 \\
120 \\
121\end{array}$ & $\begin{array}{l}210 \\
138 \\
172\end{array}$ & $\begin{array}{l}144 \\
141 \\
109\end{array}$ & $\begin{array}{l}0 \\
0.5 \\
0\end{array}$ & $\begin{array}{l}0 \cdot 5 \\
0 \\
3\end{array}$ & $\begin{array}{l}0 \\
1 \cdot 4 \\
0\end{array}$ & $\begin{array}{r}54 \\
93 \\
127\end{array}$ \\
\hline cys $D-48$ & 80 & 138 & $*$ & 98 & 88 & 122 & 85 & 77 & 101 & 86 & 72 & 52 & 0 \\
\hline
\end{tabular}

Each figure represents, for each bacterial strain, the value:

$$
\frac{\text { number of prototrophic colonies obtained with phage grown on mutant }}{\text { number of prototrophic colonies obtained with phage grown on wild-type cells }} \times 100 \text {. }
$$

Each plate was spread with $2 \times 10^{8}$ cells and $10^{\circ}$ phage which had been incubated together at $37^{\circ}$ for 10 min. The figures shown are the average of at least two separate experiments in each of which a minimum of three plates were used for each mixture.

* No crosses made. 
the majority of the prototrophic yields were less than $20 \%$ of those found using phage from wild-type cells. In contrast, $c y s-48$ behaved as unlinked to any mutant of groups $c y s A, c y s B$, (cys $C, c y s D)$ or $c y s E$. However, since day-by-day variations as great as twofold were experienced in prototrophic yields, this method can be taken to exclude only close linkage between the mutants of different groups.

(2) Linkage to the array of tryptophan markers of certain cysB mutants was shown by Demerec \& Demerec (1956); a double mutant carrying any one of several tryptophan markers and a cysB marker when treated with phage grown on wild-type cells was found to give a significant number of prototrophic colonies, in addition to the cysteine-dependent and tryptophandependent colonies resulting from transduction of one or another marker only. A number of cys mutants of each transduction group was tested for linkage with certain try markers, either in this way, or, when double mutants (try.cys) were unavailable by treatment of the cys auxotroph with phage from try donors. Plating on minimal medium supplemented with tryptophan and subsequent replication on unsupplemented minimal agar permitted the identification of any try colonies whose presence would reveal linkage of the try and cys markers (donor-phenotype selection). The results obtained indicated linkage of the try loci to the genetic markers of all the mutants of the cysB group. No such linkage was found in the tests of representatives of other cys groups (cysE-2, -8, -11, -17, -30; cysC-43, -47; cysD-42, $-44,-46 ;$ cys-48, -50 ; cys $A-1,-21)$. It would thus appear that the try loci and therefore the cys $B$ locus is not linked to either the cys $A, c y s C, c y s D$ or $c y s E$ loci, nor to $c y s-48$ or -50 .

(3) Donor-phenotype selection between phenotypically distinct, cysteineless mutants can be accomplished when the donor cells utilize a sulphur source which does not support the growth of the recipient cells; e.g. in a cross of $c y s B$ (bacteria) with $c y s A$ (phage), if $c y s A$ and $c y s B$ groups are linked, any cys $A$. cys $B^{+}$cells resulting from simultaneous transduction of the two markers will have the cys $A$ phenotype and will produce colonies on sulphite-supplemented minimal agar, on which cells of the recipient $c y s B$ strain do not grow. Colonies of this type can be distinguished from the wild-type $\left(c y s A^{+} . c y s B^{+}\right)$colonies by their inability to grow when replicated on unsupplemented minimal agar.

The simultaneous transfer of two markers is only expected when the loci concerned are closely linked. It was experimentally feasible to apply this test in the cases shown in Table 5 , which includes all possible combinations of groups except that of $c y s B$ and $c y s E$. Donor-phenotype colonies were not detected in any of these crosses, except of those mutants (cys D, cysC) already shown to be linked by prototrophic yields. In these transductions, cells of the $c y s C$ phenotype were recovered with a frequency of as high as nine times that of wild-type, showing very close linkage of the $c y s C$ and $c y s D$ loci. In all other cases, all the colonies appearing on the supplemented minimal agar plates grew on unsupplemented minimal agar and were thus prototrophic (in each transduction about 1000 colonies appearing on a total of three supplemented plates 
were replicated). The sensitivity of the test, which is restricted by the velvetpad replica technique, is such that linkage greater than about $2 \%$ should have been detected.

Abortive transduction. 'Minute' colonies attributable to abortive transduction were sought for in transduction experiments involving recipient strains of each group treated with phage grown on wild-type cells or on mutants of the same or different groups. Crosses were examined in all possible combinations among cys $A-1, B-14, C-7, D-23$ and $E-30$, between certain $c y s A$ mutants (cys-1

\begin{tabular}{|c|c|c|c|}
\hline \multirow[b]{2}{*}{$\begin{array}{c}\text { Recipient } \\
\text { bacteria }\end{array}$} & \multicolumn{2}{|c|}{ different phenotypic groups } & \multirow{2}{*}{$\begin{array}{c}\text { Percentage of } \\
\text { transduced colonies } \\
\text { which are } \\
\text { prototrophic }\end{array}$} \\
\hline & $\begin{array}{l}\text { Mutant used for } \\
\text { propagation of phage }\end{array}$ & $\begin{array}{l}\text { Supplement added to } \\
\text { minimal agar }(a)\end{array}$ & \\
\hline cys $A-1,-3$ & $\begin{array}{l}\text { cysC-7 } \\
\text { cys } D-23\end{array}$ & $\begin{array}{l}\text { Thiosulphate } \\
\text { Thiosulphate }\end{array}$ & $\begin{array}{l}100 \\
100\end{array}$ \\
\hline CysB-18 & $\begin{array}{l}\text { cys } A-1 \\
\text { cys } C-7 \\
\text { cys } D-23\end{array}$ & $\begin{array}{l}\text { Sulphite } \\
\text { Thiosulphate } \\
\text { Thiosulphate }\end{array}$ & $\begin{array}{l}100 \\
100 \\
100\end{array}$ \\
\hline cys $D-23$ & $\begin{array}{l}\text { cys } A-1 \\
\text { cys } C-7\end{array}$ & $\begin{array}{l}\text { Sulphite } \\
\text { Sulphite }\end{array}$ & $\begin{array}{r}100 \\
10\end{array}$ \\
\hline cys $E-30$ & $\begin{array}{l}\text { cys } A-1 \\
\text { cys } C-7 \\
\text { cys } D-23 \\
\text { cys } D-48\end{array}$ & $\begin{array}{l}\text { Sulphite } \\
\text { Thiosulphate } \\
\text { Thiosulphate } \\
\text { Thiosulphate }\end{array}$ & $\begin{array}{l}100 \\
100 \\
100 \\
100\end{array}$ \\
\hline cys D $-48,-50$ & $\begin{array}{l}\text { cys } A-1 \\
\text { cys } C-7\end{array}$ & $\begin{array}{l}\text { Sulphite } \\
\text { Sulphite }\end{array}$ & $\begin{array}{l}100 \\
100\end{array}$ \\
\hline
\end{tabular}

(a) Supplements were added at a concentration of $10 \mu \mathrm{g} . \mathrm{S} / \mathrm{ml}$. In each experiment, three supplemented minimal plates were spread, each with $2 \times 10^{8}$ recipient cells and $10^{9}$ phage particles. After incubation for $18 \mathrm{hr}$. at $37^{\circ}$ the plates were replicated both to minimal agar, and to minimal agar with the same supplement, and examined for colonies after incubation for $5-6 \mathrm{hr}$. at $37^{\circ}$.

and -3$)$ and among certain $c y s B$ mutants (cys-14, -18, -45, -10 and -15). These crosses included all reciprocal crosses and homologous crosses, and in addition, crosses of all mutants with phage from the lysis of the wild-type strain. CysA, cys $B$ and $c y s E$ mutants gave distinct minute colonies with phage grown either on wild-type cells or on any mutant not of the same group as the recipient. They did not produce minute colonies when treated with phage grown on mutants of the same group as the recipient (though large wild-type colonies were produced). So far as was tested, therefore, the groupings of these mutants by abortive transduction confirmed the groupings by biochemical criteria. The background growth of $c y s C$ and $c y s D$ mutants make detection of minute colonies difficult, so that it was impossible to apply the test to recipient strains of either of these two groups.

Mapping of cysB locus by three-point tests. By linkage experiments, the markers of all cysB mutants have been shown to be linked with the tryptophan loci, whereas mutants of other groups show no such linkage. The data in Table 1 confirm this close linkage of all the sites within the cysB group, and 
those of Table 4 show the absence of linkage between the markers of certain randomly chosen mutants of this group and the markers of other cys groups. Nutritional requirements, however, subdivide these mutants into three phenotypes: $\mathrm{B}_{1}$ (cysB-4, $-12,-14,-15,-16,-27,-40,-41$ and -45$)$, in which there is no perceptible growth on either sulphite or thiosulphate; $\mathrm{B}_{2}$ (cysB-18, -24 and -25), in which the ability to utilize sulphite or thiosulphate appears to result from slow adaptation by a very small proportion (c. $1 \%$ ) of the cells; and $\mathrm{B}_{3}$ (cysB-10), in which all the cells in a culture are equally able to utilize either sulphite or thiosulphate, though at a slower rate than any mutants in $c y s C$ and cys $D$ groups. In all these experiments, the concentration of sulphur supplied as thiosulphate was that amount found satisfactory when supplied as cysteine (10 $\mathrm{gg} . \mathrm{S} / \mathrm{ml}$.) (Clowes, 1958).

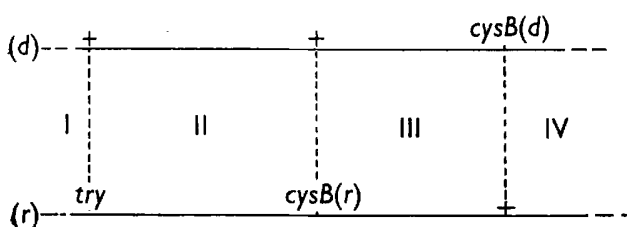

(A)

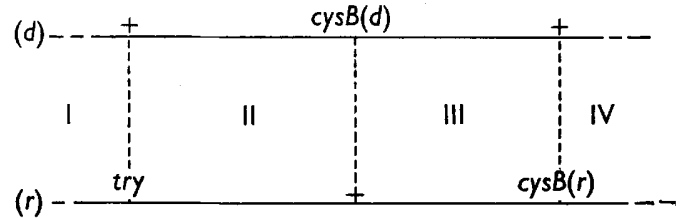

(B)

Fig. 1. Schematic representation of synapsis during transduction of a try.cysB double mutant (recipient) with phage propagated on another cys $B$ mutant (donor). Part of the chromosome of the bacterial recipient is shown in $(r)$ and the homologous part of the chromosome of the donor strain, introduced by the phage, is shown in $(d)$; the mutational sites are denoted as $\operatorname{try}, \operatorname{cys} B(r)$ and $c y s B(d)$ and their corresponding wild-type sites as + . (A) and (B) represent alternative arrangements of the cysB markers of donor and recipient.

When try.cysB double mutants are treated with phage grown on wild-type cells and plated on minimal medium plus tryptophan, the ratio of the numbers of prototrophic to tryptophanless colonies is between 0.4 and 0.7 (Demerec \& Demerec, 1956; Table 6). This ratio indicates the relative frequency of simultaneous incorporation of the wild-type alleles of the try and cysB markers, and of incorporation of that of the cysB marker only. This ratio would also be expected in crosses of the type try.cysB $(r)$ (recipient) with $c y s B(d)$ (donor), when the order of markers is try-cys $B(r)-c y s B(d)($ Fig. $1 \mathrm{~A})$, although the actual numbers of both classes would be expected to be proportionally reduced, since $\operatorname{cys} B(r)$ and $\operatorname{cys} B(d)$, between which crossing-over is required, will be closely linked (Table 1 ). However, if the cys $B(d)$ mutational site is located between the try and $c y s B(r)$ sites, (Fig. 1B) prototrophs can arise only as a result of crossingover in each of the regions I-II-III-IV (Demerec \& Demerec, 1956); whereas, crossing-over in two only of these four regions (III-IV) would give rise to tryptophanless (try.cys $\left.B(d)^{+}-c y s B(r)^{+}\right)$colonies. Since quadruple crossing-over is believed to be less frequent than double crossing-over, when the order of the markers is as shown in Fig. 1 B, the ratio of prototrophic to tryptophanless cells should be much less than the corresponding ratio when the order is as shown in Fig. 1 A, or when the phage has been propagated on the wild-type strain. The three-point crosses shown in Table 6 thus allow the order of the various sites of 
mutation within the $c y s B$ locus to be inferred with a much greater degree of precision than is possible from the results of two-point crosses of the type shown in Table 1.

\section{DISCUSSION}

Pseudoallelism and arrangement of loci. The data shown in Tables 1-4 support the conclusions of Demerec et al. (1954) that in Salmonella there are functionally undifferentiated regions in the genetic material, which are, however, divisible by mutation and recombination, as has been observed in certain other organisms (Pontecorvo, 1952; Benzer, 1955). Tests by abortive transduction gave no evidence of complementarity and thus of functional subdivision, within any group of mutants, and make it seem likely that with the exception of $c y s-48$ and -50 , the cysteineless mutants of each group established by nutritional tests which have been found to correspond to a similar group by transductional tests, have their mutational sites within the same gene locus. The exclusion of linkage greater than $c .2 \%$ between $c y s C-7$ and cys-48 (or cys-50) by donor-phenotype selection (Table 5), suggests that the genetic markers of $c y s-48$ and -50 are unlinked to those of the other mutants of similar phenotype $\left(c y s-D_{1}\right)$. Cys- 48 and -50 may thus arise by mutation in a completely separate locus, which is, however, not supported by their behaviour in nutritional and syntrophism tests already noted, nor by further tests which were unsuccessful in demonstrating syntrophy between these two mutants and others of the $c y s D_{1}$ phenotype. Alternatively, their genetic markers may be linked to those of the other cys $D$ mutants, and in the same locus in the intact bacterial genome, but that this locus is invariably fragmented at a point between the markers of $c y s-48,-50$ and the other $c y s D$ mutational sites during the incorporation of bacterial genetic material into phage particles.

The genetic markers of the cysteineless mutants used in this study appear therefore to be located in five, (or possibly six), gene loci controlling cysteine biosynthesis from sulphate; one locus controlling the reduction of sulphate to sulphite, and not more than two other loci controlling the reduction of sulphite to thiosulphate (Clowes, 1958). This is in contrast to the conclusions of Hockenhull (1949) using Aspergillus nidulans, where heterokaryon studies suggested that this synthesis was controlled by six loci, three of which control the reduction of sulphate to sulphite, and three others of which control the reduction of sulphite to thiosulphate. However, in the $c y s C$ and $c y s D$ groups, the detection of abortive transduction is rendered technically difficult by the high background growth of the mutants of these groups on minimal agar, so that further subdivision of these loci is not conclusively eliminated.

Only one of these five loci (cysB) is linked to the array of loci which have been found to control tryptophan biosynthesis (Demerec \& Demerec, 1956). The data shown in Tables 4 and 5 indicate that, among the remaining four loci, two only show linkage to each other ( $c y s C$ and $c y s D)$ and no linkage, has been demonstrated to any other locus. There is no parallel, therefore, in this system to that demonstrated in tryptophanless mutants (Demerec \& Hartman, 1956) and histidineless mutants (Hartman, 1956), where there was close linkage of all 
the loci concerned, and where the genetic order of these loci was found to follow the same sequence as the synthetic reactions in the biochemical pathway which are under their control. However, it is of interest to note that the two linked loci, $c y s C$ and $c y s D$, would appear to be concerned in consecutive reactions in the cysteine biosynthetic pathway (Clowes, 1958).

Extent of mutational changes. There have been several reports of pairs of mutants which behave as members of the same transduction group but which do not recombine to yield prototrophs by transduction (Demerec, 1955; Hartman, 1956; Yura, 1956; Demerec \& Hartman, 1956). It has been suggested that these pairs of mutants either are duplicates, i.e. reoccurrences of mutation at the same site, or that their mutational sites are so near that crossing-over does not occur (Demerec, 1956 b), or alternatively occurs too infrequently to be detected.

In other instances a mutant, which by its nutritional character and behaviour in certain transductions appears to fall in with a certain group of mutants, fails to form prototrophs by transductions with any one of a number or all of the members of this group.

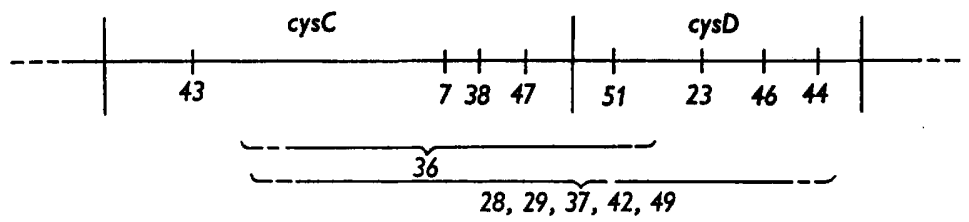

Fig. 2. Probable arrangement of mutational sites in the cysC and cysD loci. Vertical lines represent approximate location of 'single-site' mutants. 'Multiple-site' mutants are represented by a bracket covering the extent of the apparent mutation. The exact order within the two groups of mutants cysC-7, -38 and -47 , and cysD-23, -46 and -44 is not known.

This phenomenon has been interpreted on the theory that failure to recombine to produce prototrophs by transduction, indicates identity (or overlap) of the mutational sites involved. This requires that in these mutants, at each site corresponding to that at which mutation has occurred in all other mutants which fail to produce prototrophs, there is also a mutational change. Since simultaneous but independent mutations at several sites is considered to be so infrequent as to be excluded, it is suggested that there is a simultaneous. dependent mutation which extends so as to overlap all these sites. Such an event could result from a chromosomal aberration such as a deletion or an inversion. This type of mutant is, in general, less frequently isolated than the zero pairs, the only examples so far reported in Salmonella being cys $A-20$ (Demerec, 1955); hiB-22 (Hartman, 1956), and athA-10 (Yura, 1956). Similar mutants have been reported in bacteriophage T2 by Benzer (1955).

The situation existing in the linked loci cysC and cys $D$ (Table 2 ) suggests that many such mutations occur in these loci. It is assumed that the data in Table 2 reflect the mapping of mutational sites shown in Fig. 2, i.e. that $\operatorname{cys} C-43,-47,-38$ and -7 , and $c y s D-51,-23,-44$ and -46 are 'single-site mutants' whose markers are situated within the two linked loci $c y s C$ and $c y s D$, but that $c y s D-28$, 
$-29,-37,-42$, and -49 behave genetically as though in them the mutational site extended along the whole of the cysD locus and part of the cysC locus, for they are unable to produce prototrophs by transduction, both among themselves and with all the 'single-site' mutants except cys $C$-43. Similarly, cys $D-36$ behaves as though the mutation extended over part of the $c y s D$ locus including the site of cys-51, and a part of the $c y s C$ locus including all the mapped sites except that of $c y s-43$. From the data, the relative order of the mutational sites of single-site mutants cannot be fixed except that since cysC-43 produces prototrophs with the multiple site mutants, its marker is likely to be at the end of the $c y s C$ locus remote from the $c y s D$ locus and since $c y s D-23,-46$ and -44 produce prototrophs with $c y s D-36$, their markers are likely to be more distant from the cysC locus than is cysD-51. However, the order of markers within the two groups (cysC-7, -38 , and -47$)$ and (cysD-23, -44 , and -46$)$ is not known. These genetic data are supported biochemically by the correspondence of the 'single-site' mutants to those of the biochemical group $D_{1}$, which will stimulate by syntrophy all cys $A$ and $C$ mutants, and the 'multiple site' mutants to those of biochemical group $D_{2}$, which are unable to feed any of these same strains (Clowes, 1958). It has been suggested that the cysC and cysD loci control reactions which are sequential in the biosynthesis of cysteine, and that the step controlled by the $c y s D$ locus follows that controlled by the $c y s C$ locus. Both classes of mutants can grow on thiosulphate, but cysC mutants are able alternatively to utilize sulphite (Clowes, 1958). If $c y s D_{2}$ mutants are deficient of the functions controlled by both $c y s C$ and $c y s D$ they would be expected to have the same nutritional requirements as $c y s D_{1}$ mutants, but they would not accumulate the presumptive sulphite-like intermediate necessary to feed cysC. The difference in phenotype of $D_{1}$ and $D_{2}$ mutants previously noted (Clowes, 1958) can thus be explained by the genetic relationships shown in Fig. 2 where the $D_{1}$ mutants are represented as 'single-site' mutants located within the cysD locus, and the $D_{2}$ auxotrophs are shown as 'multiple-site' mutants whose site of mutation extends over parts of both the cys $D$ locus and the closely linked cys $C$ locus, resulting in a simultaneous loss of the two functions controlled by the two loci.

In this region therefore in six of fourteen mutants in the two linked groups $c y s C$ and $c y s D$, the mutational site appears to cover a region extending over more than one gene locus. None of these six strains showed any reversion to prototrophy. If the reversions observed in the case of the single-site mutants of this region are true 'back mutations' which restore the original unmutated condition, this suggests that the mutation in these 'multiple site' strains may be a true chromosomal deficiency. Within the limits of our data, it seems that the mutation may extend over the same region in all mutants except cys $D-36$, covering all known sites in the cysD locus and terminating at one end between the cluster of markers $c y s C-7,-38$, and -47 and the marker of $c y s C-43$, and at the other end at a point probably within the $c y s D$ locus.

Yanofsky (1957) has found evidence for similar phenomena among a series of mutants of Escherichia coli selected as resistant to T1 phage and found to have a concomitant requirement for tryptophan. The genetic analysis of these 
mutants is supported by more extensive biochemical data than has been possible in the present studies. The loci controlling the four or five consecutive steps of synthesis of tryptophan from anthranilic acid appear in this organism to be closely linked and to be arranged in the same sequence as the biochemical reactions under their control, as was found in Salmonella (Demerec \& Hartman, 1956). Genetic tests indicate that the T1-resistant tryptophan-requiring auxotrophs may result from deletions covering two or more of these loci, and enzyme isolations revealed that the corresponding enzymes controlled by these loci are in fact absent from the cell-free extracts of these mutants.

The high frequency of isolation and the correspondence of the mutational region in the multiple-site $c y s C . c y s D$ mutants is so far unique amongst Salmonella auxotrophs. It may be that the genetic material is unusually fragile at these points so that 'multiple-site' mutations arise more frequently in this region than elsewhere. However in Drosophila it has been suggested that deletions may be a common form of genetic change (Demerec, $1956 b$ ). If this situation has a parallel in bacteria, it is possible that the type of deletion seen in the cys $C-c y s D$ region occurs frequently in all parts of the genetic material, but that in most instances this type of change has a lethal effect, an exception being in the $c y s C-c y s D$ region. The auxotrophs used in this and in related studies in Salmonella are those in which mutations have occurred in loci controlling the biochemical synthesis of an amino-acid, vitamin or purine. These mutants were isolated in the first instance by their inability to grow on a minimal medium which supports the growth of the wild-type strain whilst growing on a complete nutrient medium. They were then further selected by their requirement for a single amino-acid, vitamin or purine (or for certain specific combinations of these growth factors) to be added to the minimal medium. Any deletion of genetic material resulting in the loss of several adjacent but functionally unrelated loci, would be expected in most instances to have a lethal effect under these conditions of selection. However, in any locus (or in any series of functionally related and adjacent loci) of such an extent that deletions of a comparable size could occur within the locus (or loci), their effect would not be lethal in the presence of the specific growth factor or of a suitable precursor. Thus it might be expected that the frequency with which deletions have a lethal effect bears an inverse relationship to the physical size of the locus, (or adjacent related loci).

An indication of the relative extent of various loci in Salmonella can be found from a comparison of the maximum crossing-over occurring between any two mutants of each locus. An estimate of these values can be obtained from the mean of the figures for reciprocal crosses of mutants as shown in Tables 1-3. These maximum values are for $c y s B, 30 \%$; cys $C, 69 \%$; $c y s D, 37 \%$ (excluding $c y s-48$ and -50 ); and for $c y s E, 28.5 \%$. The comparable figure for cys $A$ (Demerec, 1955) is calculated as $28 \%$. A similar value obtained for the extent of the two linked loci $c y s C-c y s D$ is $97 \cdot 5 \%$, whilst the maximum figure within the four linked tryptophan loci is $37 \%$ (Demerec \& Demerec, 1956) and that within the four linked histidine loci is 76.9\% (Hartman, 1956). These values suggest that the loci $c y s C$ and $c y s D$ may extend over a longer segment of the 
chromosome than that covered by other loci or by other groups of adjacent, related loci and may well account for the frequency with which multiple-site mutants are found in the $c y s C$-cys $D$ region. This would also suggest that the deletions shown in Fig. 2 are limited to within the $c y s C$ and $c y s D$ loci.

Fine structure of the cysB locus and its relation to phenotype. In Table 6, from crosses involving tryB-2.cysB-45 as recipient, the ratios of prototrophic to tryptophanless cells are similar when the phages are derived from either cysB-10 or cysB-15, to the value found when the phage is derived from wildtype cells $(0 \cdot 4-0 \cdot 7)$. This suggests the order $\operatorname{try} B-2-c y s B-45-c y s B(-10,-15)$, the use of ( ) brackets in all cases implying no particular order of those markers within the brackets. In contrast, when the phages result from lysis of either cys $B-18$ or $c y s B-24$ this ratio is reduced $(0 \cdot 09,0 \cdot 12)$, suggesting the order tryB-2-cys $B(-18,-24)-c y s B-45-c y s B(-10,-15)$. Similarly, from the crosses with tryD-11.cysB-18 as recipient (Table 6) the sequence tryD-11-cysB-14-cysB-18cys $B(-10,-15)$ is most indicated. In combination the order (tryD-11-tryB-2)cysB-14-cysB-18-cysB-45-cysB $(-10,-15)$ is given. Other experiments using either tryD-11.cys $B-12$, try $A-8 . c y s B-40$ or try $A-8 . c y s B-41$ as recipients and crossed with cysB-14, $-18,-10$ and -15 as donors give results analogous to the crosses shown in Table 6 using tryB-2.cys $B-45$ as recipient and suggest the order

(try $A-8, \operatorname{try} B-2, \operatorname{try} D-11)-c y s B-14-c y s B-18$

$$
-c y s B(-12,-40,-41,-45)-c y s B(-10,-15) \text {. }
$$

This sequence of markers within the $c y s B$ group separates the locus into at least four regions with respect to the biochemical heterogeneity, since, as already reported, cys $B-12,-14,-15,-40,-41$ and -45 are alike in being unable to replace the cysteine requirement with equivalent amounts of sulphur either as sulphite or as thiosulphate (phenotype $\mathrm{B}_{1}$ ), whereas the phenotype of cys $B-18$ permits slow adaptation to sulphite utilization (phenotype $B_{2}$ ) and that of cysB-10 permits growth on either sulphite or thiosulphate (phenotype $\mathrm{B}_{3}$ ).

Crosses using $c y s B-24$ or $c y s B-25$ as donor with each of the double mutants having one of the markers $c y s B-12,-40,-41$, or -45 as recipient, and similar to the cross shown on line 3, Table 6, indicate the order

$$
\operatorname{try}-c y s B(-24,-25)-c y s B(-12,-40,-41,-45) \text {. }
$$

Unfortunately double mutants of either cysB-24 or -25 were not available, and it has been assumed that these markers form a cluster with $c y s B-18$ and are not separated by $c y s B-14$. Further crosses of the type shown in lines 6 and 7 , Table 6, using tryD-11.cysB-18 as recipient and either $c y s B-4,-16$, or -27 as donor indicate the order try-cysB-18-cysB(-4,-16,-27). It has been assumed that these markers (cysB-4, $-16,-27)$ form a similar cluster with the other markers of the $B_{1}$ phenotype (cysB-12, $-40,-41$ and -45 ) and are not separated by $c y s B-10$.

No evidence from three-point crosses is available to map the relative order of $c y s B-10$ and -15 in the same manner. The crosses shown in Table 6 using these two mutants as donors, suggest that the markers involved in each of the four crosses can be represented diagrammatically as in Fig. 1 A, where $c y s B(r)$ represents either $c y s B-45$ or $c y s B-18$, and $c y s B(d)$ represents either 
cys $B-15$ or $c y s B-10$. The relative distances between the $c y s B$ markers of donor and recipient may then be measured by the crossing-over within region III. In these crosses, three phenotypes can be identified in the presence of the recipient phenotype, namely, wild-type (crossing-over I-III), try (crossingover II-III) and cysB (crossing-over I-II; I-IV or I-II-III-IV). Since quadruple crossing-overs (I-II-III-IV) are considered to be less frequent than

Table 6. Numbers of prototrophic and singly auxotrophic colonies obtained in transductions of a try.cysB double auxotroph with phage raised on other cysB mutants

\begin{tabular}{|c|c|c|c|c|c|c|}
\hline \multirow[b]{2}{*}{$\begin{array}{c}\text { Recipient } \\
\text { bacteria }\end{array}$} & \multirow[b]{2}{*}{$\begin{array}{l}\text { Source } \\
\text { of phage }\end{array}$} & \multicolumn{3}{|c|}{ Numbers of colonies of phenotype } & \multirow[b]{2}{*}{$\begin{array}{c}\text { Ratio of } \\
\text { prototrophs: } \\
\text { try.cys }\end{array}$} & \multirow[b]{2}{*}{$\begin{array}{c}\text { Ratio of } \\
\text { prototrophs }+ \\
\text { try.cys }{ }^{+}: \\
\text {total }\end{array}$} \\
\hline & & $\begin{array}{c}\text { try }^{+} . c y s^{+} \\
\text {(prototrophic) }\end{array}$ & $\begin{array}{l}\text { try.cys } \\
\text { (trypto- } \\
\text { phanless) }\end{array}$ & $\begin{array}{c}\text { try }^{+} . c y s \\
\text { (cysteineless) }\end{array}$ & & \\
\hline $\operatorname{tryB}-2 . \operatorname{cys} B-45$ & cys $B-10$ & $\begin{array}{r}4 \\
13 \\
9 \\
11\end{array}$ & $\begin{array}{l}14 \\
17 \\
17 \\
23\end{array}$ & $\left.\begin{array}{r}400 \\
1212 \\
1190 \\
1532\end{array}\right\}$ & $0 \cdot 501$ & $0 \cdot 025$ \\
\hline $\operatorname{try} B-2 . \operatorname{cys} B-45$ & cysB -18 & $\begin{array}{l}2 \\
7 \\
6 \\
7\end{array}$ & $\begin{array}{l}27 \\
75 \\
64 \\
74\end{array}$ & $\left.\begin{array}{r}910 \\
1780 \\
- \\
1877\end{array}\right\}$ & 0.09 & - \\
\hline $\operatorname{try} B-2 . \operatorname{cys} B-45$ & cysB-24 & $\begin{array}{l}1 \\
4 \\
2 \\
4\end{array}$ & $\begin{array}{l}10 \\
36 \\
16 \\
33\end{array}$ & $\left.\begin{array}{r}490 \\
1115 \\
- \\
1065\end{array}\right\}$ & $0 \cdot 12$ & - \\
\hline $\operatorname{tryB}-2 . \operatorname{cys} B-45$ & cys $B-15$ & $\begin{array}{r}7 \\
44 \\
56\end{array}$ & $\begin{array}{r}13 \\
100 \\
66\end{array}$ & $\left.\begin{array}{r}382 \\
3100 \\
2740\end{array}\right\}$ & 0.61 & $0 \cdot 062$ \\
\hline $\operatorname{try} D-11 . \operatorname{cys} B-18$ & cysB-14 & $\begin{array}{l}1 \\
2 \\
1\end{array}$ & $\begin{array}{l}20 \\
11 \\
17\end{array}$ & $\left.\begin{array}{l}1202 \\
1295 \\
1290\end{array}\right\}$ & 0.08 & - \\
\hline $\operatorname{try} D-11 . \operatorname{cys} B-18$ & cysB-15 & $\begin{array}{l}30 \\
35 \\
43\end{array}$ & $\begin{array}{l}60 \\
70 \\
40\end{array}$ & $\left.\begin{array}{r}205 \\
1520 \\
1346\end{array}\right\}$ & $0 \cdot 67$ & $0 \cdot 083$ \\
\hline $\operatorname{try} D-11 . c y s B-18$ & cysB -10 & 84 & 172 & 7300 & 0.49 & $0 \cdot 034$ \\
\hline $\operatorname{tryB}-2 \cdot c y s-45$ & Wild-type & $\begin{array}{l}311 \\
312\end{array}$ & $\begin{array}{l}599 \\
\mathbf{3 4 4}\end{array}$ & $\left.\begin{array}{l}557 \\
419\end{array}\right\}$ & 0.58 & 一 \\
\hline $\operatorname{try} D-11 . \operatorname{cys} B-18$ & Wild-type & $\begin{array}{l}227 \\
236\end{array}$ & $\begin{array}{l}561 \\
611\end{array}$ & $-\}$ & $0 \cdot 65$ & 一 \\
\hline
\end{tabular}

Numbers of colonies are those which appeared on a total of five plates after plating $2 \times 10^{8}$ bacteria with $5 \times 10^{9}$ phage (multiplicity 25 ) on each plate, and which were classified phenotypically by replica plating.

double crossing-overs, a close approximation of the frequency of crossing-over in region III is given by the ratio of the numbers of wild-type colonies + tryptophanless colonies to the total number of wild-type + tryptophanless + cysteineless colonies. These ratios are shown in the last column. Table 6. In both crosses involving cysB-15, this ratio is found to be greater than in the two crosses involving cysB-10, and suggests that the former marker is at the greater distance from either $c y s B-18$ or $c y s B-45$. It is suggested, therefore, that the order of markers shown in Fig. 3 represents the most probable disposition 
of the various sites within the $c y s B$ locus, and separates this locus into at least four and probably not more than five regions of secondary heterogeneity.

The inability of the biochemical tests to differentiate between the phenotypes of any of the $c y s B_{1}$ mutants and the close linkage of all mutants in the cys $B$ group make it appear unlikely that there are five distinct but closely linked loci. This was confirmed by the failure to demonstrate abortive transductions between mutants representative of the various $c y s B$ phenotypes,

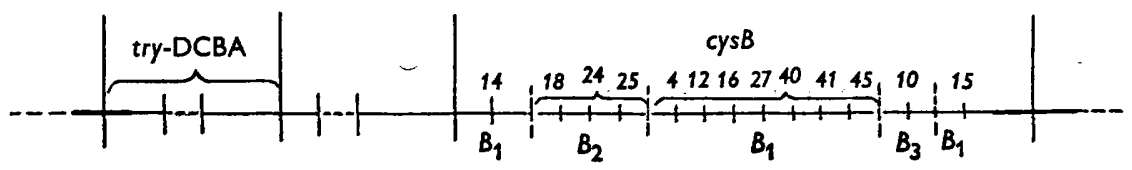

Fig. 3. Probable arrangement of mutational sites in the cysB locus. Vertical lines represent sites of mutation and when several are included within one bracket the relative order within the bracket is doubtful. $B_{1}, B_{2}$ and $B_{3}$ represent different phenotypes within the cys $B$ locus.

although ' minute' colonies resulting from abortive transduction could be clearly seen when any of these mutants were treated with lysates of either wild-type donors or other auxotrophs, including those of the $c y s A, c y s C, c y s D$ and $c y s E$ groups. The phenomenon of abortive transduction has so far been explicable by a 'cis:trans' effect, the wild-type phenotype being dependent upon the presence of a supernumary fragment of genetic material, which does not carry a mutation within the same functional locus as that in the chromosome of the recipient cell. Since the phenotypic differences found within the $c y s B$ locus are difficult to explain by leakiness or other quantitative variations, it appears that qualitative differences may exist between the mutants of the same gene locus. Other such examples of secondary biochemical heterogeneity among mutants within the same gene locus have been cited by Demerec (1956b).

I am indebted to Dr M. Demerec for the use of unpublished data, and for many helpful discussions with him and with his colleagues at the Department of Genetics, Carnegie Institution of Washington; to the Damon Runyon Memorial Fund for a Cancer Research Fellowship, and to the Wright-Fleming Institute of Microbiology, St Mary's Hospital, London, for leave of absence.

\section{REFERENCES}

Adams, M. A. (1950). Methods for the study of bacterial viruses. Meth. med. Res. $2,1$. Benzer, S. (1955). Fine structure of a genetic region in bacteriophage. Proc. nat. Acad. Sci., Wash. 41, 344.

Benzer, S. (1957). The elementary units of heredity. Symposium: 'The Chemical Basis of Heredity. Baltimore: The Johns Hopkins Press.

Clowes, R. C. (1958). Nutritional studies of cysteineless mutants of Salmonella typhimurium. J.gen. Microbiol. 18, 140.

Demerec, M. (1955). 'What is a gene?' Twenty years later. Amer. Nat. 89, 5.

Demerec, M. (1956a). Terminology and Nomenclature. In Genetic Experiments with Bacteria. Publ. Carneg. Inst. 612, 1.

Demerec, M. (1956 b). A comparable study of certain gene loci in Salmonella. Cold Spr. Harb. Symp. quant. Biol. 21, 113. 
Demerec, M., Blomstrand, I. \& Demerec, Z. E. (1955). Evidence of complex loci in Salmonella. Proc. nat. Acad. Sci., Wash. 41, 359.

Demerec, M. \& Demerec, Z. E. (1956). Analysis of linkage relationships in Salmonella by transduction techniques. In Brookhaven Symp. Biol. 8, 75.

Demerec, M. \& Hartman, Z. (1956). Tryptophan mutants in Salmonella typhimurium. In Genetic Studies with Bacteria. Publ. Carneg. Inst. 612, 5.

Demerec, M., Moser, H., Hemmerly, J., Blomstrand, I., Demerec, Z. E., Fitzgerald, P. L., Glover, S. W., Hanson, J. F., Nielson, F. J. \& Yura, T. (1954). Bacterial Genetics. I. Yr. Bk. Carneg. Inst. 53, 225.

Hartman, P. E. (1956). Linked loci in the control of consecutive steps in the primary pathway of histidine synthesis in Salmonella typhimurium. In Publ. Carneg. Inst. $612,35$.

Hershey, A. D. \& Chase, M. (1952). Independent functions of viral protein and nucleic acid in the growth of bacteriophage. J. gen. Physiol. 36, 39.

Hockenhull, D. J. D. (1949). The sulfur metabolism of mold fungi. The use of biochemical mutant strains of Aspergillus nidulans in elucidating the biosynthesis of cystine. Biochem. biophys. Acta, 3, 326.

Lederberg, J. \& Lederberg, E. M. (1952). Replica plating and indirect selection of bacterial mutants. J. Bact. 63, 399.

Ozeki, H. (1956). Abortive transduction in purine-requiring mutants of Salmonella typhimurium. In Genetic Studies with Bacteria. Publ. Carneg. Inst. 612, 97.

Pontecorvo, G. (1952). Genetical analysis of cell organisation. Symp. Soc. exp. Biol. 6, 218.

Stocker, B. A. D., Zinder, N. D. \& Lederberg, J. (1953). Transduction of flagellar characters in Salmonella. J. gen. Microbiol. 9, 410.

YANOFSKY, C. (1957). Enzymatic studies with a series of tryptophan mutants of Escherichia coli. J. biol. Chem. 224, 783.

YURA, T. (1956). Evidence of non-identical alleles in Purine-requiring mutants of Salmonella. In Genetic Studies with Bacteria. Publ. Carneg. Inst. 612, 77.

ZINDER, N. D. (1955). Bacterial transduction. Symp. Genetic Recombination. J. cell. comp. Physiol. 45, Suppl. 2, 23.

Zinder, N. D. \& Lederberg, J. (1952). Genetic exchange in Salmonella. J. Bact. 64,679 . 